\title{
Coming Off Prescribed Psychotropic Medications: Insights from Their Use as Recreational Drugs
}

\section{Fabrizio Schifano}

Psychopharmacology, Drug Misuse, and Novel Psychoactive Substances Research Unit, School of Life and Medical Sciences, University of Hertfordshire, Hatfield, UK

\section{Introduction}

Cosci and Chouinard [1] present a very elegant and thought-provoking overview. They comment extensively on the potential possessed by a range of therapeutically prescribed (under appropriate medical control) psychotropics being associated with a short-/long-term withdrawal syndrome when discontinued. This is a relevant clinical topic; indeed, in parallel with a decline in both benzodiazepines (BDZs) and Z-drugs (e.g., zaleplon; zolpidem; and zopiclone) in the UK, prescriptions of antidepressants (ADs); second-generation anti-psychotics; and gabapentinoids have significantly increased $[2,3]$.

\section{Recreational and Prescription Psychotropics:}

\section{Terminology Issues}

Recreational, abused drugs (e.g., cannabinoids; cocaine; and MDMA/ecstasy) appear to increase dopaminergic signalling in ventral striatal regions, including the nucleus accumbens, a key site of the mesolimbic reward pathway $[4,5]$. Increased activity in striatal dopaminergic signalling pathways is likely associated with the subjective rewarding, euphoric, and reinforcing effects of such molecules. Conversely, reduced dopaminergic transmission in the limbic system plays a role in drug craving; withdrawal; and relapse into compulsive drug intake [5]. Furthermore, recreational drugs are considered to possess no, or very limited, therapeutic value.

When referring to therapeutically prescribed molecules, however, there are levels of clinical terminology confusion [6]. In fact, the related terms "misuse," "abuse," "dependence," and "addiction" are often used without standardized definitions in the literature. From a pharmacovigilance [7] perspective, "misuse" is the intentional and inappropriate use of a product other than as prescribed or not in accordance with the authorized product information, whilst "abuse" is the intentional non-therapeutic use of a product for a perceived reward, including "getting high"/euphoria [8].

Conversely, dependence is characterized per se by tolerance and/or withdrawal symptoms [9], with "withdrawal" however not necessarily including the occurrence of physical signs and symptoms [10]. Finally, "addiction" is characterized by a further range of issues, e.g., compulsive substance use; craving; and continued use despite its adverse consequences $[6,11,12]$. Hence, withdrawal symptoms that occur upon discontinuation of medications prescribed for valid medical reasons do karger@karger.com

(C) 2020 S. Karger AG, Basel

www.karger.com/pps

Karger"
Fabrizio Schifano

School of Life and Medical Sciences, University of Hertfordshire College Lane Campus

Hatfield, Herts AL10 9AB (UK)

F.Schifano@ herts.ac.uk 
not suggest per se either a substance-related [13] or an addiction disorder [6]. This may well be the case with both ADs [14-16] and BDZs [17].

Syndromes of withdrawal, a more appropriate term than "discontinuation" [18], occur with most recreational and a range of prescribed drugs [15]. These syndromes may include the following features: (a) rebound, e.g., the re-occurrence of the original symptoms for which the index medication was prescribed; (b) withdrawal, including both rebound and new (unrelated) symptoms; and (c) persistent post-withdrawal disorder, characterized by a return of the original illness at higher severity, often associated with additional features [1].

Withdrawal syndromes have been interpreted in light of the concept of behavioural toxicity [1, 19-21]. In 1968, DiMascio and Shader [22] specifically addressed the behavioural toxicity of psychotropics. They referred to the pharmacological actions of a drug that, within the dose range in which it has been found to possess clinical utility, may produce a range of psychological and behavioural alterations, thus limiting the capacity of the individual or constituting a hazard to his/her well-being. Such a concept was revisited by Fava et al. [21] in 2016. It may thus be of interest to analyse these phenomena in a population where psychotropic drugs are clearly misused/abused to outline similarities and differences.

\section{Misuse/Abuse of High-Dosage Medications: The \\ Psychonauts' World}

In clinical psychiatry settings, the intentional misuse and abuse of therapeutically prescribed medicines may well be an unusual observation. It is here argued, however, that these same prescription molecules, when ingested by those with a substance abuse history; at largely supra-therapeutic dosages (e.g., pregabalin, venlafaxine, and quetiapine); and/or with modalities that increase their bioavailability (e.g., loperamide), may be associated with a clear-cut "reward" sensation. This is at odds with other reports, suggesting that medication misuse may be associated only with soothing effects but little else [6].

Indeed, a range of prescribed medications are currently being used recreationally, typically at high-/super-high dosages, as new/novel psychoactive substances (NPS) [23]. Within both online drug forum communities and social networks, there are some educated/informed users (the "psychonauts") [24] who are keen to "test" a range of molecules, including prescription psychotropics, to achieve specific mindsets. Their information is routinely being shared online [24], and vulnerable subjects, including both children/adolescents and psychiatric patients, may hence be at risk of accessing these "pro-drug" data [25].

Psychonauts are a clinical "niche," and their idiosyncratic levels of medication intake are better scrutinized with the help of the netnographic research approach [26]. This approach should be interpreted as a "magnifying lens," aimed at shedding further light on the putative misuse, abuse, and dependence potential of those psychotropics being prescribed by practicing psychiatrists.

The focus will be here on the different withdrawal, misuse, abuse, and dependence issues associated with the typically high-/very high-dosage recreational intake of a range of prescribed psychotropics, including GABAergics, ADs, ketamine and related drugs, anti-psychotics, gabapentinoids, and over-the-counter opiates/opioids.

\section{GABAergics (BDZs, "Z-Drugs," GABA-A/GABA-B Agonists)}

\section{Prescribed and Designer/Exotic BDZs}

According to a recent survey of European-wide emergency department admissions, the most frequently misused BDZs were clonazepam, diazepam, and alprazolam, respectively [27]. In parallel, a range of NPS belonging to the BDZ class have recently appeared on the street/online/virtual markets and are known as "legal/exotic/designer" BDZs. Exotic BDZs were either tested, but not approved, as medicinal compounds or are derivatives of currently prescribed BDZs. For most of them, only very little pharmacology and toxicity knowledge is available [26]. Most typically, online BDZ purchasers are per definition not aware if they are taking traditional, designer, or counterfeit BDZs. Although there are a few hundreds of exotic BDZs discussed within the NPS community [28], a non-participant, multilingual, qualitative/netnographic study recently focused on those 29 exotic BDZs which have been formally identified as NPS by the European Monitoring Centre for Drugs and Drug Addiction (EMCDDA) [26]. They can be ingested, snorted, or injected (for an overview of related clinical features, see Table 1) [29].

\section{Z-Drugs}

Although sharing a similar mechanism of action with BDZs, Z-drugs appeared on the market as safe substitutes for BDZs, purportedly having both a reduced abuse potential and propensity to induce less tolerance and withdrawal due to improved pharmacokinetics [30]. Withdrawal symptoms of Z-drugs are similar to those observed 


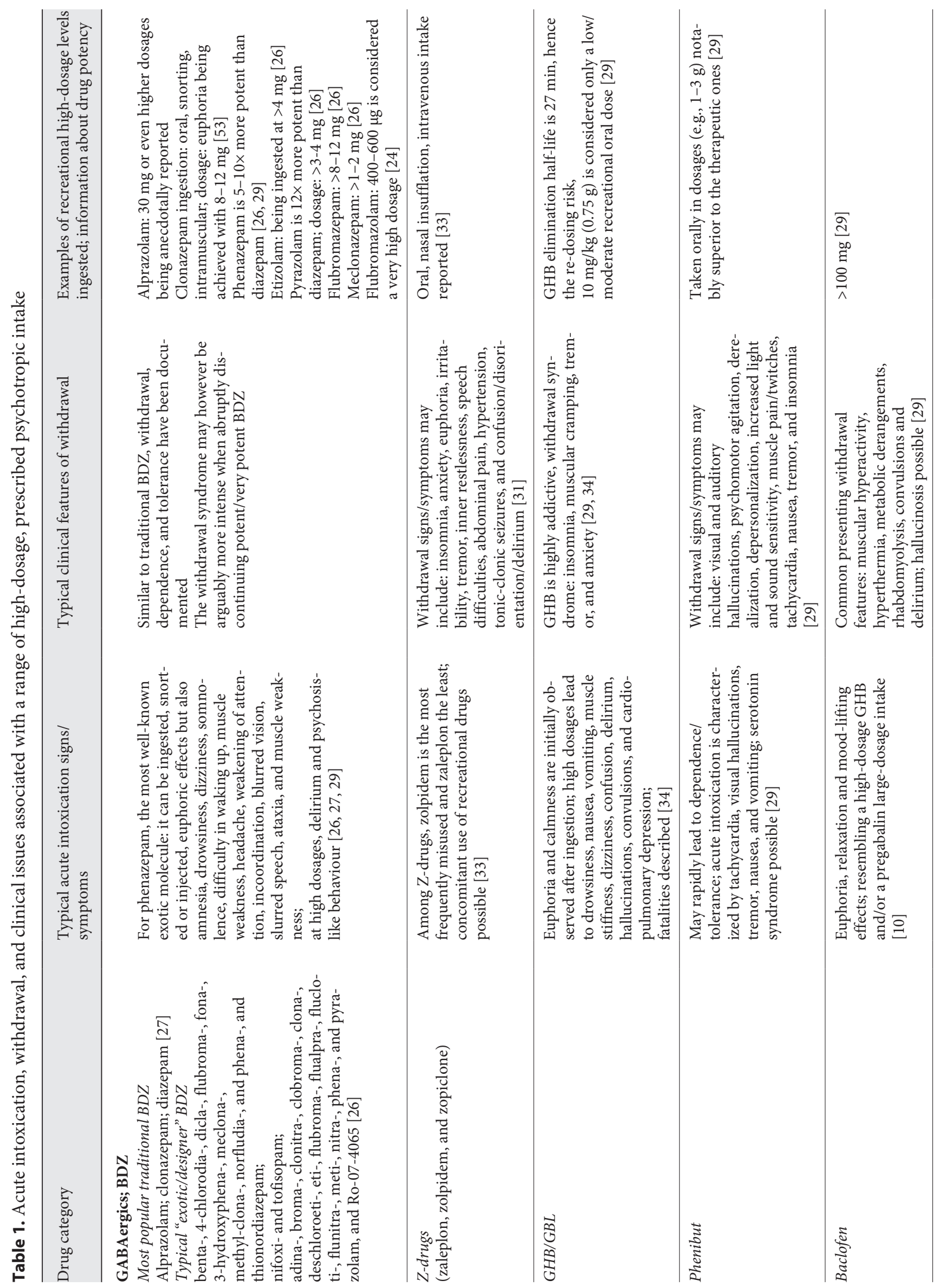




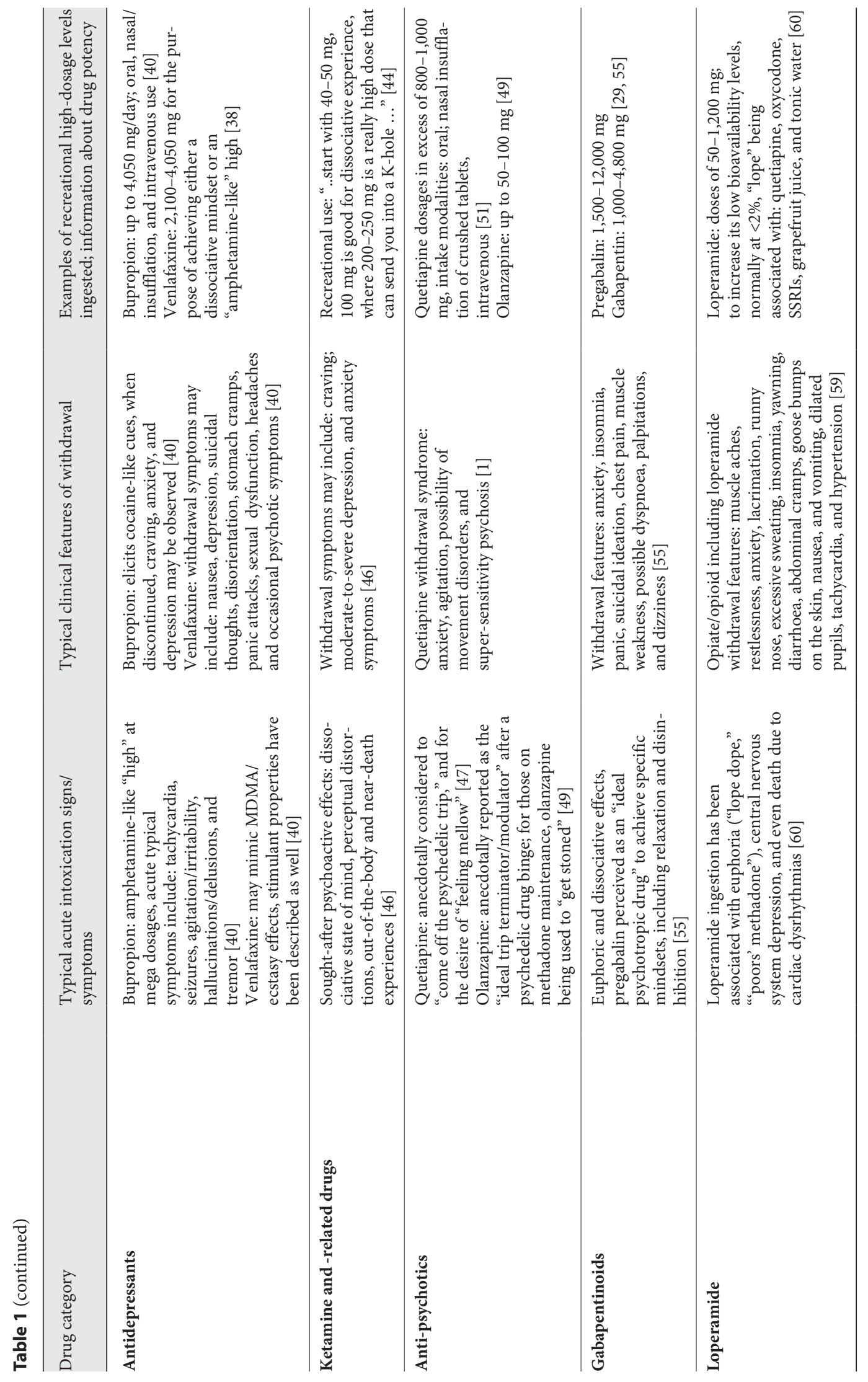


with BDZs (Table 1) [31]. However, their idiosyncratic routes of administration and the high-dosage intake may well increase the risk of Z-drug withdrawal issues [32].

Schifano et al. [33] analysed the adverse drug reaction (ADR) data sets provided by the European Medicines Agency (EMA) through the EudraVigilance (EV) system. An overall total of 33,240 (e.g., 23,420 for zolpidem; 9,283 for zopiclone; and 537 for zaleplon) misuse/abuse/dependence and withdrawal-related ADRs, corresponding to some 6,246 unique patients, were identified. Out of these 3 molecules, zolpidem and zopiclone presented with the same dependence risk, but zolpidem was the most frequently associated with withdrawal issues. Zaleplon was the least reported for these ADRs (Table 1).

\section{$\gamma$-Hydroxybutyric Acid/ $\gamma$-Butyrolactone}

Currently used in some countries to treat narcolepsy and alcohol withdrawal, $\gamma$-hydroxybutyric acid (GHB; "liquid ecstasy") intake is associated with both increased central dopamine (DA) levels and activation of GABA$\mathrm{A} / \mathrm{B}$ receptors [34]. The $\mathrm{GHB}$ withdrawal syndrome has been well characterized (Table 1). In the UK, Corkery et al. [34] described $159 \mathrm{GHB} / \gamma$-butyrolactone (GBL)-associated fatalities; most (79\%) were accidental and GHB/ GBL alone was implicated in $37 \%$ of cases.

\section{Phenibut}

Phenibut (PB) is openly available online as both a nootropic and a dietary supplement. When misused at high dosages (Table 1), it acts as GABA-A/-B receptor agonist, whilst stimulating $\mathrm{DA} /$ serotonin neurotransmission as well. Its use may rapidly lead to dependence; withdrawal signs/symptoms may include visual and auditory hallucinations (Table 1) [29].

\section{Baclofen}

Baclofen is a GABA-B agonist showing both anxiolytic and analgesic properties; high-dosage baclofen intake is associated with euphoria, relaxation, and anxietyblocking effects. Baclofen should always be withdrawn gradually (Table 1) [29].

\section{Antidepressants}

Out of all ADs, bupropion and venlafaxine have emerged as increasingly being misused and abused [35]. Both high/very high (e.g., up to 4,050 mg/day, roughly 14 times higher than the maximal therapeutic dosage with oral, nasal, and intravenous use) stimulant effects of bu- propion have been reported (Table 1), consistent with its action both as a selective inhibitor of noradrenaline (NA) and DA re-uptake. Bupropion is a cathinone derivative, resembling the remaining large number of synthetic cathinone NPS [36]. Typical bupropion idiosyncratic dosage abusers may present with a history of drug addiction and/or are inmates (Table 1) [35,37]. At mega dosages, even venlafaxine can be misused and abused (Table 1) [38]; this is consistent with desvenlafaxine, which is an inhibitor of NA transporter activities, further increasing the rate of DA turnover in the prefrontal cortex [39]. In line with these observations, both the lastdecade EMA and the UK-based Yellow Card Scheme pharmacovigilance ADR data [40] showed that, in comparison with venlafaxine, bupropion may possess a higher stimulant-like recreational activity. Conversely, the occurrence of a withdrawal syndrome was confirmed to be a significant issue for venlafaxine-treated patients [40].

\section{Ketamine and Related Drugs}

Ketamine psychiatric prescriptions are on the increase [41], and the UK National Institute of Clinical Excellence (NICE) is currently reviewing the possibility of its derivative esketamine being used for treatment-resistant depression. However, because of ketamine-related compound-associated psychosis and misuse, this decision has sparked levels of controversy [42]. Ketamine acts as an $\mathrm{N}$-methyl-D-aspartate (NMDA) receptor antagonist, whilst inhibiting both the voltage-gated $\mathrm{Na} / \mathrm{K}$ channels, serotonin, and DA re-uptake. All these actions are likely contributing to both its significant psychoactive effects and addictive liability issues (Table 1) [43, 44]. The occurrence of painful ketamine-associated urinary dysfunction [45] can facilitate persistent ketamine intake because of its analgesic properties. There are a range of ketamine/"special-K"-related molecules being widely misused by psychonauts, including methoxetamine ("special M") [46] and dextromethorphan or DXM ("green triangle"), an over-the-counter cough/cold remedy [29].

\section{Anti-Psychotics (Quetiapine, Olanzapine, and Clozapine)}

Commonly prescribed in the range of $400-800 \mathrm{mg} /$ day, quetiapine ("Susie Q;" "Q ball," and "Maq ball" if associated with cocaine and marijuana, respectively) ap- 
pears to be the most documented anti-psychotic being abused either on its own or in combination [17]. Its extended-release formulation may be less frequently misused and abused due to the delayed (by approximately $3 \mathrm{~h}$ ) and blunted (by approximately 67\%) serum peak; the tablet coating may also make snorting of the crushed tablets quite problematic [47]. Prison inmates and opioid addicts seem to represent the most at-risk populations. Quetiapine psychotropic effects are associated with both increased levels of DA in the nucleus accumbens area [48] and $\mathrm{D} 2$ receptor blockade, although norquetiapine-related NA re-uptake blockade, 5-HT7 antagonist properties, and sigma receptor activation may contribute to its misuse liability [for a review, see 16].

Conversely, olanzapine at high dosage has been anecdotally reported as the "ideal trip terminator/modulator" $[49,50]$. These misusing liability levels may be associated with: olanzapine-related activity on GABA-A receptors hence the associated sedation; the rewarding glutamatergic stimulation of the ventral tegmental area dopaminergic neurons; the 5HT2C and histamine/H1 antagonist properties, and the potent inhibiting action on the muscarinic M1 receptors [for a review, see 35].

All voluntary EMA database reports relating to both quetiapine (2005-2016) and olanzapine (2004-2016) were recently analysed [34]. From the EMA database, 18,112 $(8.64 \%$ of 209,571$)$ and $4,178(7.58 \%$ of 55,100$)$ ADR reports of misuse/abuse/dependence and withdrawal were associated with quetiapine and olanzapine, respectively. The resulting proportional reporting ratios suggested that the withdrawal-related ADRs were more frequently reported for quetiapine, with a proportional reporting ratio of 5.25 in comparison with olanzapine [51].

Although clozapine is known to present with a range of well-known side-effects, only anecdotal description is available relating to its putative withdrawal syndrome. Chiappini et al. [52] recently analysed the 2005-2018 EMA dataset of ADRs to identify and describe possible clozapine withdrawal-related issues. Out of 11,847 clozapine-related ADRs, some 258 were withdrawal related [52].

\section{Gabapentinoids}

Following initial reports from this Psychotherapy and Psychosomatics [53], the gabapentinoids pregabalin and gabapentin have been clearly identified as possessing a distinct potential for misuse [54]. Chiappini and Schifano [55] aimed at assessing cases of gabapentinoid misuse or dependence as reported to the EMA EV database. All vol- untary reports of both gabapentin (2004-2015) and pregabalin (2006-2015) were retrieved. Some 7,639 (6.6\% of a total of 115,616$)$ and $4,301(4.8 \%$ of 90,166$)$ ADR reports of misuse/abuse/dependence were associated with pregabalin and gabapentin, respectively. Misuse/abuse/dependence-related entries were more frequently reported for pregabalin than gabapentin; frequent levels of co-ingestion with opiates/opioids were identified, especially in fatalities.

Overall, gabapentinoids may induce a "liking" (euphoric high) subjective feeling but more limited levels of "wanting"/behavioural dependence [for an overview, see 56]. Indeed, patients may report pleasant stimulation and euphoria only when using supra-therapeutic/mega dosages (e.g., 1,500-12,000 mg) of pregabalin [56]. Hence, one could wonder if there may be a different/unclear range of neurotransmitter involvement and receptor activation intensity in case of mega-dosage pregabalin ingestion (Table 1).

\section{Opiates/Opioids and Loperamide}

A massive, recent, worldwide increase in opiate/opioid prescription levels has been identified, with fentanyl being a reason of particular concern [57-59]. Within the over-the-counter abuse ("pharming") opiate/opioid scenario, the anti-diarrhoeal loperamide has increasingly been reported by psychonauts as a recreational drug [60]. Loperamide acts as a potent $\mu$-opioid receptor agonist, albeit with predominantly peripheral activity on the myenteric plexus. High-dosage loperamide ingestion has been associated with euphoria [60]; different techniques are being used to increase its low bioavailability levels (Table 1) [35, 60].

\section{Conclusions}

The current editorial has taken inspiration from the thought-provoking paper by Cosci and Chouinard [1]; they focused on the withdrawal syndromes associated with a range of therapeutic-dosage, medically prescribed, psychotropic intake. The issues associated with these same psychotropics, albeit ingested as advised by the psychonauts, have been described here.

It is here suggested that when selected psychotropic medications are self-administered at mega - as opposed to therapeutic - dosage levels, the associated withdrawal, persistent post-withdrawal, and overall behavioural toxicity issues may be particularly relevant. Indeed, when ta- 
pering down a therapeutic-dosage $\mathrm{AD}$, symptoms most typically are both mild/go untreated, and resolve spontaneously [21]. However, when high-/mega-dosage ADs $[37,61]$, gabapentinoids [62], or BDZs [26] are discontinued, the intense withdrawal-related symptoms will always need proper, long-term specialist attention. Second, the occurrence of a persistent post-withdrawal disorder is only occasionally observed with both anti-psychotics (e.g., tardive dyskinesia and super-sensitivity psychosis) and ADs (e.g., mood fluctuations) [16]. Conversely, with highdosage medications (e.g., negative affect; dysphoria; and protracted insomnia for opiates/opioids) [63] post-withdrawal issues are very frequently reported. Finally, the range of psychotropic intake-related behavioural toxicity syndromes, which are at times observed at therapeutic dosages, may include alterations in mood, perceptual, cognitive, and psychomotor functions [21], but also both "paradoxical" (e.g., increased anxiety and rage, as opposed to sedation, with BDZs) and "pendular" (e.g., excessive/ euphoric mood-lifting modifications with ADs) drug effects [22]. Conversely, at mega psychotropic dosages, the range of the above clinical effects are being typically observed, indeed representing the sought-after effects. This is especially true for venlafaxine (MDMA-like perceptual disturbances); bupropion (excessive mood lifting and pendular drug alterations) [64]; pregabalin (perceptual disturbances/dissociative effects); and quetiapine (intense psychomotor function retardation effects). Further, the therapeutic-dosage BDZ intake may be associated with paradoxical effects only in selected subgroups, e.g., patients with personality disorder [65] or the elderly [66]. Conversely, the high-dose, highly potent BDZs/novel BDZs are often ingested to achieve proper stimulant/aggressive - as opposed to sedative - effects $[65,67]$

Increasing levels of access to the web over the past 15 years or so may have contributed to the current scenario of prescribed-drug misuse and abuse, with social networks having played a role in the aggressive marketing/ distribution of prescription drugs from rogue websites [25]. However, for most prescription molecules here discussed, including gabapentinoids, one should here emphasize that pre-marketing processes were not able to appropriately identify their misuse and abuse potential. Pre-authorization trials, however, typically involve the administration of carefully controlled, daily limited, therapeutic dosages, and subjects with a current/previous history of drug misuse are excluded [23]. Hence, the possible potential of molecules for abuse will be fully appreciated only when the real-world client population, involving vulnerable individuals, is exposed to it. Because of a likely post-marketing reporting bias (e.g., clinicians typically flagging only those molecules which have already been identified as at-risk for misuse and abuse), pharmacovigilance should identify a range of technical tools and approaches to go beyond voluntary reporting systems.

At high/very high dosage, a range of medications, including ADs, anti-psychotics, and gabapentinoids, can be self-administered as proper drugs of abuse. Physicians should be vigilant when prescribing drugs with an abuse/ misuse/diversion potential [68] and carefully evaluate the risk for some clients to be prone to ingest high-/megadosage medications, often in combination with alcohol and illicit drugs. Prescribers should hence be aware of the possibility of feigning psychiatric symptoms in order to obtain specific medications [69].

\section{Disclosure Statement}

F.S. was a member of the UK Advisory Council on the Misuse of Drugs (ACMD; 2011-2019) and is currently a member of the EMA Advisory Board (Psychiatry).

\section{Funding Sources}

Nil to be reported.

\section{References}

1 Cosci F, Chouinard G. Acute and persistent withdrawal syndromes following discontinuation of psychotropic medications. Psychother Psychosom. 2020 Apr;1-24.

2 Taylor S, Annand F, Burkinshaw P, Greaves F, Kelleher M, Knight J, et al. Dependence and withdrawal associated with some prescribed medicines: an evidence review. London: Public Health England; 2019.

3 Buhagiar K, Ghafouri M, Dey M. Oral antipsychotic prescribing and association with neighbourhood-level socioeconomic status: analysis of time trend of routine primary care data in England, 2011-2016. Soc Psychiatry Psychiatr Epidemiol. 2020 Feb;55(2):165-73.

4 Di Chiara G, Tanda G, Bassareo V, Pontieri F, Acquas E, Fenu S, et al. Drug addiction as a disorder of associative learning. Role of nucleus accumbens shell/extended amygdala dopamine. Ann N Y Acad Sci. 1999 Jun;877:461-85.

5 Diana M, Melis M, Muntoni AL, Gessa GL. Mesolimbic dopaminergic decline after cannabinoid withdrawal. Proc Natl Acad Sci USA. 1998 Aug;95(17):10269-73.
6 Balon R, Silberman EK, Starcevic V, Cosci F, Freire RC, Nardi AE, et al. Benzodiazepines, antidepressants and addiction: A plea for conceptual rigor and consistency. J Psychopharmacol. 2019 Nov;33(11):1467-70.

7 Felicetti P, Trotta F, Bonetto C, Santuccio C, Brauchli Pernus Y, Burgner D, et al.; Brighton Collaboration Vasculitis Working Group. Spontaneous reports of vasculitis as an adverse event following immunization: A descriptive analysis across three international databases. Vaccine. 2016 Dec;34(51):6634-40. 
8 MedDRA Term Selection: points to consider. Release 4.9 Based on MedDRA Version 18.0 March 2015. Available from: http://www. meddra.org/how-to-use/support-documentation/english.

9 NIDA. Tolerance, Dependence, Addiction: What's the difference? Available from: https:// teens.drugabuse.gov/blog/post/tolerancedependence-addiction-whats-difference.

10 Schifano F. Substance misuse in the workplace. In: Ghodse $\mathrm{AH}$, editor. Addiction at Work: Tackling Drug Use and Misuse in the Workplace. Aldershot, UK: Gower Publishing Ltd; 2005. pp. 53-67.

11 Heinz A, Daedelow LS, Wackerhagen C, Di Chiara G. Addiction theory matters-Why there is no dependence on caffeine or antidepressant medication. Addict Biol. 2020 Mar; 25(2):e12735.

12 Palmer RH, Brick LA, Chou YL, Agrawal A, McGeary JE, Heath AC, et al. The etiology of DSM-5 alcohol use disorder: evidence of shared and non-shared additive genetic effects. Drug Alcohol Depend. 2019 Aug;201:147-54.

13 Nielsen M, Hansen EH, Gøtzsche PC. What is the difference between dependence and withdrawal reactions? A comparison of benzodiazepines and selective serotonin re-uptake inhibitors. Addiction. 2012 May;107(5):900-8.

14 Fava GA, Gatti A, Belaise C, Guidi J, Offidani E. Withdrawal Symptoms after Selective Serotonin Reuptake Inhibitor Discontinuation: A Systematic Review. Psychother Psychosom. 2015;84(2):72-81.

15 Fava GA, Benasi G, Lucente M, Offidani E, Cosci F, Guidi J. Withdrawal Symptoms after Serotonin-Noradrenaline Reuptake Inhibitor Discontinuation: systematic Review. Psychother Psychosom. 2018;87(4):195-203.

16 Baldessarini RJ, Tondo L. Effects of Treatment Discontinuation in Clinical Psychopharmacology. Psychother Psychosom. 2019; 88(2):65-70.

17 Balon R, Chouinard G, Cosci F, Dubovsky SL, Fava GA, Freire RC, et al. International Task Force on Benzodiazepines. Psychother Psychosom. 2018;87(4):193-4.

18 American Psychiatric Association. Diagnostic and Statistical Manual of Mental Disorders. 5th ed. Washington, DC, American Psychiatric Association Publishing: 2013.

19 Fava GA, Rafanelli C. Iatrogenic Factors in Psychopathology. Psychother Psychosom. 2019;88(3):129-40.

20 Schifano F, Magni G. MDMA ("ecstasy") abuse: psychopathological features and craving for chocolate: a case series. Biol Psychiatry. 1994 Dec;36(11):763-7.

21 Fava GA, Cosci F, Offidani E, Guidi J. Behavioral Toxicity Revisited: Iatrogenic Comorbidity in Psychiatric Evaluation and Treatment. J Clin Psychopharmacol. 2016 Dec; 36(6):550-3.

22 DiMascio A, Shader RI. Behavioral toxicity of psychotropic drugs. I. Definition. II. Toxic effects on psychomotor functions. Conn Med. 1968 Aug;32(8):617-20.
23 Schifano F, Papanti GD, Orsolini L, Corkery JM. The consequences of drug misuse on post-marketing surveillance. Expert Rev Clin Pharmacol. 2016 Jul;9(7):867-71.

24 Orsolini L, St John-Smith P, McQueen D, Papanti D, Corkery J, Schifano F. Evolutionary Considerations on the Emerging Subculture of the E-psychonauts and the Novel Psychoactive Substances: A Comeback to the Shamanism? Curr Neuropharmacol. 2017;15(5):731-7.

25 Orsolini L, Francesconi G, Papanti D, Giorgetti A, Schifano F. Profiling online recreational/prescription drugs' customers and overview of drug vending virtual marketplaces. Hum Psychopharmacol. 2015 Jul;30(4): $302-18$.

26 Orsolini L, Corkery JM, Chiappini S, Guirguis A, Vento A, De Berardis D, et al. 'New/Designer Benzodiazepines': an analysis of the literature and psychonauts' trip reports. Curr Neuropharmacol. 2020, DOI: 10.2174/15701 59X18666200110121333.

27 Lyphout C, Yates C, Margolin ZR, Dargan PI, Dines AM, Heyerdahl F, et al.; Euro-DEN Research Group. Presentations to the emergency department with non-medical use of benzodiazepines and Z-drugs: profiling and relation to sales data. Eur J Clin Pharmacol. 2019 Jan;75(1):77-85.

28 Schifano F, Napoletano F, Chiappini S, Guirguis A, Corkery JM, Bonaccorso S, et al. New/ emerging psychoactive substances and associated psychopathological consequences. Psychol Med. 2019 Jul:1-13. Epub 2019 Jul 22.

29 Schifano F, Orsolini L, Duccio Papanti G, Corkery JM. Novel psychoactive substances of interest for psychiatry. World Psychiatry. 2015 Feb;14(1):15-26.

30 Gunja N. The clinical and forensic toxicology of Z-drugs. J Med Toxicol. 2013 Jun;9(2):155-62.

31 Franc A, Kubová K, Elbl J, Muselík J, Vetchý D, Šaloun J, et al. Diazepam filled hard capsules intended for detoxification of patients addicted to benzodiazepines and Z-drugs. Eur J Hosp Pharm Sci Pract. 2019 Jan;26(1):10-5.

32 Victorri-Vigneau C, Dailly E, Veyrac G, Jolliet P. Evidence of zolpidem abuse and dependence: results of the French Centre for Evaluation and Information on Pharmacodependence (CEIP) network survey. Br J Clin Pharmacol. 2007 Aug;64(2):198-209.

33 Schifano F, Chiappini S, Corkery JM, Guirguis A. An Insight into Z-Drug Abuse and Dependence: An Examination of Reports to the European Medicines Agency Database of Suspected Adverse Drug Reactions. Int J Neuropsychopharmacol. 2019 Apr;22(4):270-7.

34 Corkery JM, Loi B, Claridge H, Goodair C, Corazza O, Elliott S, et al. Gamma hydroxybutyrate (GHB), gamma butyrolactone (GBL) and 1,4-butanediol (1,4-BD; BDO): A literature review with a focus on UK fatalities related to non-medical use. Neurosci Biobehav Rev. 2015 Jun;53:52-78.

35 Schifano F, Chiappini S, Corkery JM, Guirguis A. Abuse of Prescription Drugs in the Context of Novel Psychoactive Substances
(NPS): A Systematic Review. Brain Sci. 2018 Apr;8(4):E73.

36 Schifano F, Napoletano F, Arillotta D, Zangani C, Gilgar L, Guirguis A, et al. The clinical challenges of synthetic cathinones. Br J Clin Pharmacol. 2020 Mar;86(3):410-9.

37 Vento AE, Schifano F, Gentili F, Pompei F, Corkery JM, Kotzalidis GD, et al. Bupropion perceived as a stimulant by two patients with a previous history of cocaine misuse. Ann Ist Super Sanita. 2013;49(4):402-5.

38 Francesconi G, Orsolini L, Papanti D, Corkery JM, Schifano F. Venlafaxine as the 'baby ecstasy'? Literature overview and analysis of web-based misusers' experiences. Hum Psychopharmacol. 2015 Jul;30(4):255-61.

39 Weikop P, Kehr J, Scheel-Krüger J. The role of alpha1- and alpha2-adrenoreceptors on venlafaxine-induced elevation of extracellular serotonin, noradrenaline and dopamine levels in the rat prefrontal cortex and hippocampus. J Psychopharmacol. 2004 Sep;18(3):395403.

40 Schifano F, Chiappini S. Is there a potential of misuse for venlafaxine and bupropion? Front Pharmacol. 2018 Mar;9:239

41 Wilkinson ST, Toprak M, Turner MS, Levine SP, Katz RB, Sanacora G. A Survey of the Clinical, Off-Label Use of Ketamine as a Treatment for Psychiatric Disorders. Am J Psychiatry. 2017 Jul;174(7):695-6.

42 Devlin H. Ketamine-like drug for depression gets UK licence. The Guardian, December 19, 2019. Available from: https://www.theguardian.com/science/2019/dec/19/ketamine-likedrug-depression-uk-licence-esketamine.

43 Andrade C. Oral ketamine for depression, 1: Pharmacologic considerations and clinical evidence. J Clin Psychiatry. 2019 Apr;80(2): $19 f 12820$.

44 Reddit, 2020. Available from: https://www. reddit.com/r/Drugs/comments/1eyrbq/i_ just_bought_some_ketamine_what_dose_ and roa for/.

45 Wu P, Wang Q, Huang Z, Wang J, Wu Q, Lin T. Clinical staging of ketamine-associated urinary dysfunction: a strategy for assessment and treatment. World J Urol. 2016 Sep;34(9): 1329-36.

46 Corazza O, Assi S, Schifano F. From "Special K" to "Special M": the evolution of the recreational use of ketamine and methoxetamine. CNS Neurosci Ther. 2013 Jun;19(6):454-60.

47 Murphy D, Bailey K, Stone M, Wirshing WC. Addictive potential of quetiapine. Am J Psychiatry. 2008 Jul;165(7):918.

48 Peyrière $\mathrm{H}$, Diot $\mathrm{C}$, Eiden $\mathrm{C}$, Petit $\mathrm{P}$, Réseau de centres de d'Addictovigilance. Abuse Liability of Quetiapine (Xeroquel ${ }^{\circledR}$ ). Therapie. Epub 2015 Aug 4.

49 Valeriani G, Corazza O, Bersani FS, Melcore C, Metastasio A, Bersani G, et al. Olanzapine as the ideal "trip terminator"? Analysis of online reports relating to antipsychotics' use and misuse following occurrence of novel psychoactive substance-related psychotic symptoms. Hum Psychopharmacol. 2015 Jul;30(4):249-54. 
50 James PD, Fida AS, Konovalov P, Smyth BP. Non-medical use of olanzapine by people on methadone treatment. BJPsych Bull. 2016 Dec;40(6):314-7.

51 Chiappini S, Schifano F. Is there a potential of misuse for quetiapine? Literature review and analysis of the European Medicines Agency/ European Medicines Agency Adverse Drug Reactions' database. J Clin Psychopharmacol. 2018 Feb;38(1):72-9.

52 Chiappini S, Schifano F, Corkery JM, Guirguis A. Focus on Clozapine Withdrawal- and Misuse-Related Cases as Reported to the European Medicines Agency (EMA) Pharmacovigilance Database. Brain Sci. 2020 Feb; 10(2):E105.

53 Schifano F, D'Offizi S, Piccione M, Corazza O, Deluca P, Davey Z, et al. Is there a recreational misuse potential for pregabalin? Analysis of anecdotal online reports in comparison with related gabapentin and clonazepam data. Psychother Psychosom. 2011;80(2):118-22.

54 Deeb S, Wylie FM, Torrance HJ, Scott KS. An insight into gabapentin and pregabalin in Scottish prisoners. J Anal Toxicol. Epub 2020 Jan 2.

55 Chiappini S, Schifano F. A decade of gabapentinoid misuse: an analysis of the European Medicines Agency's "suspected adverse drug reactions" database. CNS Drugs. 2016 Jul; 30(7):647-54
56 Schifano F, Chiappini S. Pregabalin: A range of misuse-related unanswered questions. CNS Neurosci Ther. 2019 May;25(5):659-60.

57 Chen CL, Jeffery MM, Krebs EE, Thiels CA, Schumacher MA, Schwartz AJ, et al. Longterm trends in postoperative opioid prescribing, 1994 to 2014. J Am Acad Orthop Surg Glob Res Rev. 2020 Jan;4(1):e19.00171.

58 Schifano F, Chiappini S, Corkery JM, Guirguis A. Assessing the 2004-2018 fentanyl misusing issues reported to an international range of adverse reporting systems. Front Pharmacol. 2019 Feb;10:46.

59 Arillotta D, Schifano F, Napoletano F, Zangani C, Gilgar L, Guirguis A, et al. Novel opioids: systematic web crawling within the epsychonauts' scenario. Front Neurosci. 2020 Mar; 14:149.

60 Schifano F, Chiappini S. Is there such a thing as a 'lope' dope? Analysis of loperamide-related European Medicines Agency (EMA) pharmacovigilance database reports. PLoS One. 2018 Oct;13(10):e0204443.

61 Quaglio G, Schifano F, Lugoboni F. Venlafaxine dependence in a patient with a history of alcohol and amineptine misuse. Addiction. 2008 Sep;103(9):1572-4.
62 Carrus D, Schifano F. Pregabalin misuse-related issues; intake of large dosages, drugsmoking allegations, and possible association with myositis: two case reports. J Clin Psychopharmacol. 2012 Dec;32(6):839-40.

63 Kakko J, Alho H, Baldacchino A, Molina R, Nava FA, Shaya G. Craving in Opioid Use Disorder: From Neurobiology to Clinical Practice. Front Psychiatry. 2019 Aug;10:592.

64 Khurshid KA, Decker DH. Bupropion insufflation in a teenager. J Child Adolesc Psychopharmacol. 2004;14(1):157-8.

65 Michel L, Lang JP. [Benzodiazepines and forensic aspects]. Encephale. 2003 Nov-Dec; 29(6):479-85. French.

66 Reddy MS, Achary U, Harbishettar V, Sivakumar PT, Varghese M. Paradoxical reaction to benzodiazepines in elderly - Case series. Asian J Psychiatr. 2018 Jun;35:8-10.

67 Albrecht B, Staiger PK, Hall K, Kambouropoulos N, Best D. Motivational drive and alprazolam misuse: A recipe for aggression? Psychiatry Res. 2016 Jun;240:381-9.

68 Marsden J, White M, Annand F, Burkinshaw $\mathrm{P}$, Carville S, Eastwood B, et al. Medicines associated with dependence or withdrawal: a mixed-methods public health review and national database study in England. Lancet Psychiatry. 2019 Nov;6(11):935-50.

69 Pierre JM. Abuse of psychiatric medications: Not just stimulants and benzodiazepines. Curr Psychiatry. Jan;18(1):10-16. 